\title{
Treatment of chronic heart block with the Lucas induction coil pacemaker
}

\author{
C. O. Record ${ }^{1}$, P. Sleight, A. J. Gunning, J. M. Kenworthy-Browne, and M. Richings \\ From the Cardiac Department and the Nuffield Department of Surgery, \\ The Radcliffe Infirmary, Oxford
}

The Lucas fixed rate induction coil pacemaker has been used in Oxford for the past 4 years. Forty-five patients were treated with 54 units and $7 I$ per cent of the units used functioned normally for 12 months. There was only one further failure among the 24 pacemakers followed up for longer than this period (up to 51 months; mean 25.7 months). The advantages of the system over totally implanted systems are economy, freedom from elective operative exchange of generator every 2 years, and ease of follow-up. For those patients who do not require a demand pacemaker, we suggest that the system is a valuable alternative to implantable units, and may with greater experience become the treatment of choice.

The treatment of chronic heart block by longterm cardiac pacing is now firmly established (Sowton, 1967). Totally implanted pacemakers suffer from the disadvantage that generator or battery failure necessitates surgical replacement at/or within 2 years. The Lucas ${ }^{2}$ inductively coupled system (Abrams, Hudson, and Lightwood, I960; Taylor, 1966; Clarke, Evans, and Milstein, I97I) avoids this complication in that the generator is readily accessible for battery changing and can be exchanged should a fault appear. We have used this system over the past 4 years and report here our experience with 45 patients.

\section{Patients}

Twenty-three male and 22 female patients aged between 27 and 87 were treated. Thirty-four had persistent heart block and I I intermittent. Thirtysix had suffered from Adams-Stokes attacks, 5 from symptoms of low cardiac output, and 2 from severe heart failure. One patient in addition suffered from severe headache, due to a wide pulse pressure which disappeared with pacing. One patient developed complete heart block after aortic valve replacement and one after repair of an atrial septal defect together with mitral valve replacement (for a septum primium defect with cleft mitral valve).

Five patients suffered from diabetes mellitus, one with peripheral vascular disease necessitating

Received 18 March 197 I.

1 Present address Nuffield Department of Clinical Medicine, The Radcliffe Infirmary, Oxford.

2 Joseph Lucas Ltd., Monkspath, Shirley, Solihull, Warwickshire, England. lower limb amputation. Fourteen suffered from a variety of complicating medical or surgical conditions and 2 patients had a heavy alcohol intake which may or may not have been causally related to their block. Several patients had previously received implanted pacemakers which had failed and it was our early experience with these which led us to change to the Lucas system.

\section{Pacemaker insertion and operation}

The Lucas equipment has been described previously (Abrams and Norman, 1964; Taylor, I966; Clarke et al., I97I). Essentially it consists of a totally implanted internal coil with epi or endocardial leads and a generator connected to an external coil. The generator is fitted with a wheel for regulating the discharge frequency, which slows as the battery becomes depleted. The impulse rate is brought back to $70 / \mathrm{min}$ or thereabouts daily by advancing the discharge regulator wheel.

For endocardial pacing, a unipolar coiled wire electrode is inserted via external or internal jugular veins or tributaries of the subclavian vein; insertion of the internal coil is a simple surgical procedure which can be satisfactorily accomplished either by surgeons or, in our experience, by physicians in the catheter room. We have found that the most suitable position for the internal coil is over the front of the chest but have also utilized the anterior abdominal wall. A drawback of this latter situation is the greater volume of subcutaneous tissue which allows the external coil to stray away from the internal coil with consequent loss of pacing.

Postoperatively the patients are taught to time their radial pulses and to adjust the generator impulse regulator to maintain the pulse at $70 / \mathrm{min}$. 
They are provided with two sets of generator and external coil and are taught to change sets each week. In a predominantly elderly group of patients many of whom are deaf and have poor vision, this, one may think, is an impossible task. However, in our experience, satisfactory training, though laborious, has always been achieved. Relatives, and in their absence, local authority nurses, add encouragement and more active support when necessary. (For full details see Clarke et al., 1971.)

Patients are followed up in the pacemaker clinic initially one month after discharge and later, if uncomplicated, at 6-monthly intervals. Rhythm strips and a chest $x$-ray are taken at yearly intervals. At each attendance the impulse voltage is measured across the forearms (lead I) on an oscilloscope and this is compared with previous readings. This has proved in no way helpful in detecting impending pacemaker failure and is probably unnecessary. Faulty generators occur uncommonly but when suspected they are exchanged and returned to the makers for checking and overhaul. External wires and coils are replaced as necessary.

\section{Results}

Forty-five patients have been followed for $78 \mathrm{I}$ months. These patients were treated with a total of 54 pacemaking systems. A change from epicardial to endocardial pacing or vice versa, or a need for repositioning the endocardial electrode has been counted as a new system (excluding electrodes which were repositioned within 7 days of insertion). Early in our experience patients were paced de novo with an epicardial system, but later, as our confidence in the reliability of the Lucas electrode catheter increased, we tried endocardial pacing initially in all cases.

Long-term results (Table I) Of the pacemaker systems inserted, 70.9 per cent were troublefree for at least 12 months. Twentyfour pacemakers functioned normally for more than 12 months, 14 of which were endocardial and ro epicardial. There was only one failure among these latter pacemakers; an epicardial pacemaker which failed from exit block after 34 months of use. There were 13 pacemaker failures during the 12 months after insertion, and 7 of these were due to displacement of the endocardial wire which occurred after a mean period of 6.4 months.

The longest uncomplicated pacemaker follow-up at the time of the review was 5I months and the mean follow-up of those pacemakers functioning for more than 12 months was 25.7 months. The actuarially calculated survival curve (Fig.) encourages us to think that the risks of pacing failure are very low after the initial problems are overcome.

Deaths Nine patients died but in 5 of them death appeared unrelated to the pacemaker. One died of secondary haemorrhage following aortic valve replacement after 30 months of uncomplicated pacing. Another died of heart failure 5 months after aortic valve replacement and after 5 months of uncomplicated pacing. A further patient died of uraemia and a fourth of chronic bronchitis and congestive cardiac failure after 23 months of uncomplicated pacing. The fifth patient who had a ro-year history of ischaemic heart disease died at home two months after admission for treatment for recurrent congestive cardiac failure. $\mathrm{He}$ had been satisfactorily paced for Io months.

In 4 patients pacemaker dysfunction probably resulted in death, that is a mortality of 7.6 per cent for a mean follow-up period of 14.5 months. Two of these patients died suddenly after 6 and 8 months of pacing though careful checking, within 24 hours of death, had failed to reveal any pacemaker malfunction. Two further patients almost certainly died from pacemaker dysfunction. One suffered from competing ventricular rhythms after fixed rate pacing and unfortunately died on the day before elective exchange of his fixed rate Lucas pacemaker for an implantable 'demand' device. Necropsy revealed extensive myocardial fibrosis from coronary artery disease. The other patient died suddenly at home after Io months of pacing. Though only middle-aged she had

TABLE I Actuarially calculated pacemaker survival. Total no. of pacemakers $=54$. Deaths unrelated to pacemaker considered as followed-up to the time of death $=5$

\begin{tabular}{|c|c|c|c|c|c|c|c|c|c|c|c|c|}
\hline & \multicolumn{12}{|c|}{ Interval (mth) } \\
\hline & 3 & 6 & 9 & $I 2$ & 15 & 18 & $2 I$ & 24 & 27 & 30 & 33 & 36 \\
\hline $\begin{array}{l}\text { No. of pacemakers } \\
\text { completing interval } \\
\text { Per cent surviving } \\
\text { Standard error }(\%)\end{array}$ & \begin{tabular}{l}
\multicolumn{1}{l}{49} \\
$88 \cdot 7$ \\
4.4
\end{tabular} & $\begin{array}{l}40 \\
86 \cdot 5 \\
4.8\end{array}$ & $\begin{array}{l}30 \\
76 \cdot 5 \\
6 \cdot 3\end{array}$ & $\begin{array}{l}24 \\
70 \cdot 9 \\
7 \cdot 0\end{array}$ & $\begin{array}{l}22 \\
70 \cdot 9 \\
7 \cdot 0\end{array}$ & $\begin{array}{l}18 \\
70 \cdot 9 \\
7 \cdot 0\end{array}$ & $\begin{array}{l}14 \\
70 \cdot 9 \\
7 \cdot 0\end{array}$ & $\begin{array}{l}10 \\
70.9 \\
7.0\end{array}$ & $\begin{array}{r}9 \\
70 \cdot 9 \\
7 \cdot 0\end{array}$ & $\begin{array}{r}7 \\
70 \cdot 9 \\
7 \cdot 0\end{array}$ & $\begin{array}{c}6 \\
70 \cdot 9 \\
7 \cdot 0\end{array}$ & $\begin{array}{c}4 \\
59 \cdot 1 \\
12 \cdot 3\end{array}$ \\
\hline
\end{tabular}




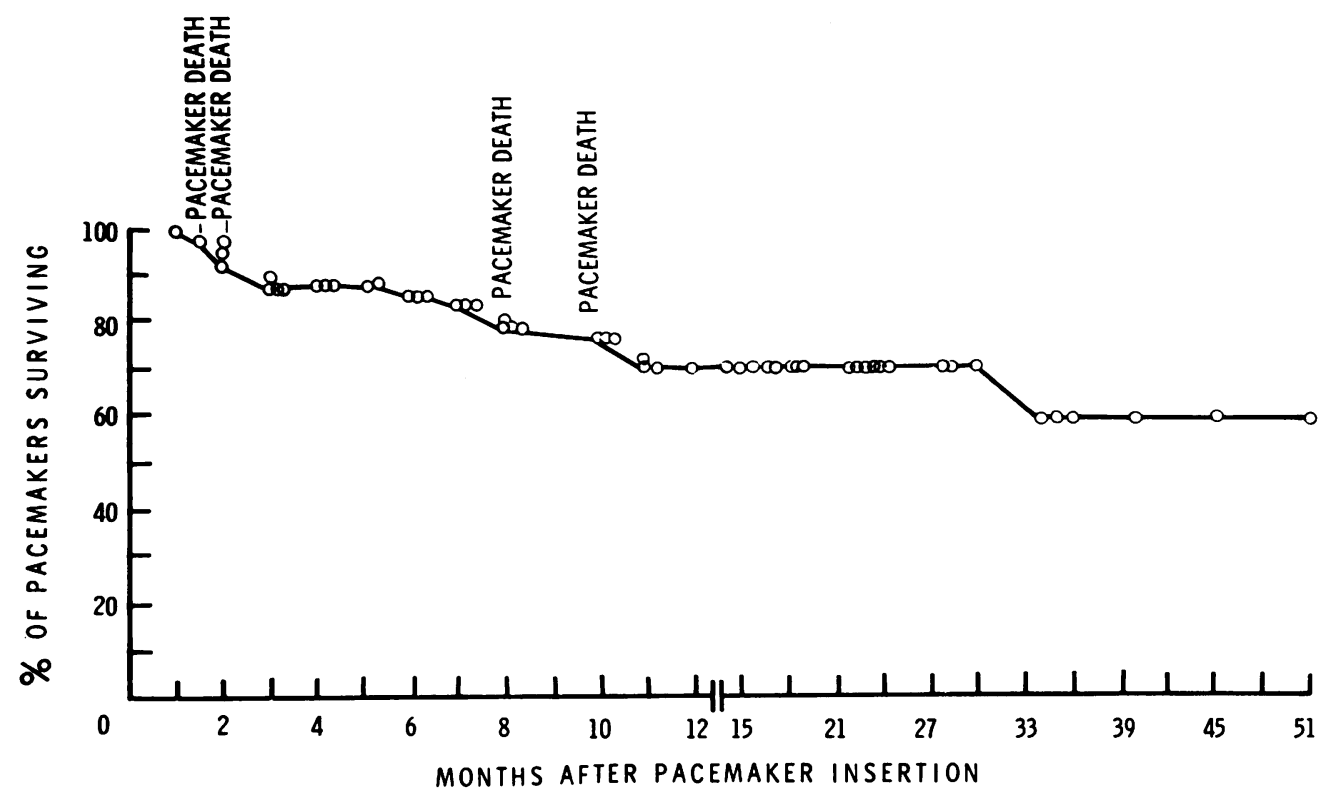

FIG. Actuarially calculated pacemaker survival curve. Total pacemakers $=54$; deaths unrelated to pacemaker considered as followed up to time of death $=5$. (After Pike and Roe, 1963.)

complained of numerous transient giddy episodes, but pacemaker function was repeatedly normal when monitored. Coroner's necropsy failed to reveal any definite cause of death. (These latter four cases are considered pacemaker failures in Table $I$ and the Fig.)

Complications Voluntary muscle and diaphragmatic spasm was a commonly encountered and irritating complaint. It could generally be overcome by offsetting the position of the external coil or placing a pad of gauze between external and internal coils. In one case it was necessary to supply an external coil with a reduced number of copper wire turns, thus inducing a lower voltage in the internal ring. In general, careful positioning of the indifferent internal wire and suture to the sternal periosteum minimized this complication.

Internal coil failure 6 months after insertion occurred in one patient and was thought to be due to defective insulation with entry of body fluids. Replacement of this coil was followed by the only case of sepsis with a chronically discharging sinus around the implanted coil. Atrophy of the subcutaneous tissues overlying the internal coil has occurred in one case but so far no breakdown of the skin has occurred.

External component failures were dealt with by immediate replacement. Generator failures were very uncommon but if any defect was suspected by the patient then the generator was replaced and checked. Fracture of the external wire close to the union with the generator was common, the average lifetime of each wire being 6 to 12 months.

Competition between intermittent sinus rhythm and Lucas fixed rate pacing proved to be a problem in only 2 cases. In one case pacing resulted in runs of ventricular ectopics and this could not be overcome by slowing the impulse discharge rate. This patient died on the day before elective exchange of the pacemaker for a 'demand' system. The intermittent sinus rhythm of a further patient could not be captured except with rapid pacing but interference could be cut to a minimum by reducing the impulse discharge rate to $30-$ $40 / \mathrm{min}$. Now we would elect to pace this type of patient with an implanted demand pacemaker.

\section{Discussion}

The Lucas inductively coupled system has a number of advantages over totally implanted systems and perhaps the greatest of these is the easy accessibility of the generator for battery changing and for exchange, should a fault occur. Totally implanted pacemakers now rarely fail within the first 18 months (8 out of 131, Goldstein et al., 1970; I out of 53, Forbes et al., 1968). Chardack and Greatbatch (1968) report a 9.4 per cent failure rate for 53 Medtronic pacemakers followed up for 
I 8 months, but after 25 months their failure rate had risen to 38 per cent (for 21 pacemakers). Different authors recommend elective exchange of implanted pacemakers at between I5 and 30 months (Gotsman et al., 1968; Goldstein et al., 1970; Chardack and Greatbatch, 1968). Though the nuclear powered pacemakers may overcome this difficulty, we feel that it will be several years before one can be sure that these generators will function reliably for the theoretical length of their power supply. Inductively coupled pacemakers do not suffer from the need for elective exchange after about 2 years and our experience suggests that failures after the first I2 months of pacing are unusual (Fig.).

Follow-up of inductively coupled pacemakers is a simple procedure requiring no special electronic equipment to detect alteration in pulse wave characteristics which accompany battery depletion of implanted pacemakers. Outpatient assessment can be reduced to 6- or 12-monthly intervals in uncomplicated cases, a major advantage over transcutaneous pacemakers where frequent attendance for assessment and dressing is necessary (Conway, Seymour, and Gibbons, 1969). An increased liability of the catheter to become displaced was also noted by these authors and from this complication the inductively coupled system is also free.

Analysis of the pacemaker failures (Table 2) shows that 50 per cent were due to late displacement of the endocardial wire. After I2 months of pacing the endocardial wire seemed stable as this difficulty no longer occurred. Harris et al. (I968) reported two pacemaker deaths due to late displacement of endocardial electrodes, and Goldstein et al. (1970) reported this complication twice. In other series this does not seem to have been an important cause of failure of implanted units. Various precautions were taken to minimize early displacement of the endocardial wire, including careful positioning of the electrode and the provision of adequate wire to ensure a gentle curved intracardiac course. Though the experience of the operators over the course of the study was variable

\section{TABLE 2 Pacemaker failures}

\begin{tabular}{|c|c|}
\hline $\begin{array}{l}\text { Slipped endocardial wire } \\
\text { (Range: } 2-1 \text { I months; mean } 6.4 \text { months) } \\
\text { (Including } 2 \text { transferred to epicardial systems) } \\
\text { Exit block (epicardial) } \\
\text { Defective internal coil } \\
\text { Deaths }\end{array}$ & $\begin{array}{l}2 \\
1 \\
4\end{array}$ \\
\hline Total & I4 \\
\hline
\end{tabular}

this is unlikely to be the explanation for displacement occurring after a mean period of 6.4 months after insertion.

Exit block was a late complication of two epicardial pacemakers both of which were subsequently replaced with endocardial systems which in our experience were free from this phenomenon. The inductively coupled system has an advantage over implanted pacemakers in that in these cases the discharge voltage can be increased simply by switching the generator from normal to high power. Three of our patients who have a high pacing threshold are run permanently on 'high power', though the usefulness of this facility is limited frequently by incapacitating voluntary muscle or diaphragmatic contractions.

Four sudden deaths have been attributed to pacemaker failure though ventricular fibrillation may have been responsible for three and was almost certainly responsible for one of these. Our overall mortality, excluding non-pacemaker deaths, compares favourably with other series $(7 \cdot 6 \%$ for a mean follow-up period of 14.6 months).

It is often said that the patient with a totally implanted system has the great advantage that he can forget his pacemaker and live a worry free life. In our experience this hope is illusory when one considers the need for frequent hospital checks and elective generator replacement every $18-30$ months. Indeed, many of our patients remark positively on the confidence they have in the simplicity of the system and, perhaps more important, on the ease with which they can substitute their spare generator if they have any anxiety. Several patients have experienced both implanted and Lucas units and all prefer the latter. An extreme illustration is given by our 33-year-old housewife with 2 small children who had frequent Adams-Stokes attacks from heart block associated with rheumatoid disease. In 1966 she suffered II 6 days in hospital, both at our hands and in several other centres, with both epi and endocardial systems. She now has an epicardial Lucas system which has functioned without trouble since July 1967.

Another possible objection, namely the danger of accidental displacement of the external coil, has not in practice been the problem which we feared, since all the patients take very good care with this and with the connexion of the eternal coil to the generator.

The cost of the inductively coupled system per patient is in the region of $£ 100$, very much less than the cheapest implantable units 
available. When one considers that the generators have an indefinite lifetime, do not need to be replaced every two years, and have a very low failure rate (Fig.), then the economic advantages of the system become obvious.

When long-term fixed rate pacing over a number of years is anticipated, particularly in young and middle-aged patients, it is suggested that inductively coupled pacing is a valuable alternative to totally implanted units and may with greater experience become the method of choice.

We are indebted to Dr. M. C. Pike who advised on the calculation and presentation of the pacemaker survival results.

\section{References}

Abrams, L. D., Hudson, W. A., and Lightwood, R (1960). A surgical approach to the management of heart-block using an inductive coupled artificial cardiac pacemaker. Lancet, $1,1372$.

Abrams, L. D., and Norman, J. C. (1964). Experience with inductive coupled cardiac pacemakers. Annals of the New York Academy of Sciences, III, 1030.

Chardack, W. H., and Greatbatch, W. (1968). Follow up reliability report. Medtronic, Inc. October 1968.
Clarke, M., Evans, D. W., and Milstein, B. B. (197I). Long-term pacing with an inductive coupling system. British Heart fournal, 33, 65.

Conway, N., Seymour, J., and Gibbons, D. (1969). Long-term transcutaneous endocardial pacing in management of complete heart block. British Heart fournal, 31, 163.

Forbes, W., Green, G. D., Shaw, G. B., and Bain, W. (1968). Long-term transvenous cardiac pacing with Chardack-Greatbatch (Medtronic) pacemaker. British Medical fournal, 2, 13

Goldstein, S., Moss, A. J., Rivers, R. J., Jr., and Weiner, R. S. (1970). Transthoracic and transvenous pacemakers. A comparative clinical experience with $\mathrm{I} 3 \mathrm{I}$ implantable units. British Heart fournal, 32, 35.

Gotsman, M. S., Piller, L. W., Beck, W., Barnard, C. N., and Schrire, V. (1968). Some problems of permanent artificial pacing. British Medical fournal, $1,343$.

Harris, A., Redwood, D., Davies, M., and Davies, G. (1968). Causes of death in patients with complete heart block and artificial pacemakers. British Heart Fournal, 30, 14.

Pike, M. C., and Roe, F. J. C. (1963). An actuarial method of analysis of an experiment in two-stage carcinogenesis. British fournal of Cancer, 17, 605 .

Sowton, E. (1967). Cardiac pacemakers and pacing. Modern Concepts of Cardiovascular Disease, 36, 31.

Taylor, A. B. (1966). Experience with cardiac pacemaking. British Medical fournal, 2, 543

Requests for reprints to Dr. C. O. Record, Nuffield Department of Clinical Medicine, The Radcliffe Infirmary, Oxford. 